\title{
Combination of Laser Material Deposition and Laser Surface Processes for the Holistic Manufacture of Inconel 718 Components
}

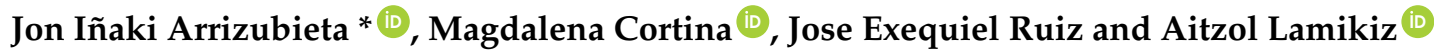 \\ Department of Mechanical Engineering, University of the Basque Country, Plaza Torres Quevedo 1, Bilbao 48013, \\ Spain; magdalena.cortina@ehu.eus (M.C.); joseexequiel.ruiz@ehu.eus (J.E.R.); aitzol.lamikiz@ehu.eus (A.L.) \\ * Correspondence: joninaki.arrizubieta@ehu.eus; Tel.: +34-946-013-932
}

Received: 27 June 2018; Accepted: 18 July 2018; Published: 20 July 2018

\begin{abstract}
The present work proposes a novel manufacturing technique based on the combination of Laser Metal Deposition, Laser Beam Machining, and laser polishing processes for the complete manufacturing of complex parts. Therefore, the complete process is based on the application of a laser heat source both for the building of the preform shape of the part by additive manufacturing and for the finishing operations. Their combination enables the manufacture of near-net-shape parts and afterwards removes the excess material via laser machining, which has proved to be capable of eliminating the waviness resulting from the additive process. Besides, surface quality is improved via laser polishing so that the roughness of the final part is reduced. Therefore, conventional machining operations are eliminated, which results in a much cleaner process. To validate the capability of this new approach, the dimensional accuracy and surface quality as well as the microstructure of the resulting parts are evaluated. The process has been validated on an Inconel 718 test part, where a previously additively built-up part has been finished by means of laser machining and laser polishing.
\end{abstract}

Keywords: laser; additive manufacturing; laser beam machining; laser polishing; waviness; roughness; Inconel 718

\section{Introduction}

Laser Material Processing is an alternative to many traditional manufacturing processes, such as arc welding, electrochemical machining, hand polishing, electron beam welding, etc. Laser Material Processing's main characteristic is the use of a high-power laser as a heat source, which results in a very high concentration of the energy density that reduces the Heat Affected Zone (HAZ) and thermally induced distortions [1].

One of the laser-based processes that is experiencing a continuous growth is the Laser Metal Deposition (LMD). This additive manufacturing (AM) technique consists on generating a melt pool on the surface of the substrate, while wire or powder shaped filler material is added simultaneously [2]. Besides, LMD enables to obtain near-net-shape parts, which reduces the amount of wasted material [3,4]. Regarding environmental impact considerations, if material reductions as high as $50 \%$ with respect to the initial part are required during the manufacturing process, AM becomes environmentally friendlier compared with machining and forging [5]. In the same way, the aeronautical industry uses the buy-to-fly ratio as an efficiency factor, since it relates the weight of the part that really flights with the weight of the initial part stock. Laser Material Deposition can reduce the buy-to-fly ratio below 1.5:1, comparable to laser welding processes [6]. However, LMD manufactured parts do not meet the final surface roughness and dimensional requirements, and a finishing operation is always required [7]. Usually, conventional machining is applied for the finishing of the parts. 
Another laser-based process that has found a niche in the market is the Laser Beam Machining (LBM), where the laser beam is directly applied for melting and vaporizing unwanted material from the substrate surface [8]. As the LBM is a laser-based process, no cutting tools are required, and materials can be machined regardless their hardness [9]. In addition, LBM process applies a laser beam (usually smaller than $75 \mu \mathrm{m}$ beam diameter) directly for removing surface material. Hence, this process is especially suitable for the machining of small details on hard materials [10]. Moreover, high aspect-ratio grooves and holes can also be achieved [11] and almost no HAZ is generated when nano or femto pulse-duration lasers are used [12]. Nevertheless, as Dubey et al. stated, LBM process is not fully developed, and it is still waiting to its industrial use [8].

LBM does not always provide the desired surface quality and a finishing operation is therefore required. To this end, highly skilled operators using abrasive tools have traditionally performed finishing operations manually. For instance, Peng et al., proposed the Abrasive Flow Machining for removing the falling effect and the powder adhesion generated during AM [13].

An alternative to reduce the surface roughness of previously manufactured parts, which has caught the interest of many researchers, is the laser polishing (LP) [14-16]. In LP, peaks of the surface roughness are melted, and the material is redistributed in the valleys due to the surface tension and the gravity [17]. Therefore, when laser-polishing material is not removed, nor the final shape of the part is modified, but material is relocated while melted. To improve the understanding of the effect of LP on additively manufactured parts, Marimuthu et al., studied the influence of the melt pool dynamics on the resulting surface topology and roughness [18].

Other authors have studied experimentally the improvement of the surface quality when AM and LP are combined. For example, Zhihao et al., studied the surface roughness reduction of additively built-up parts using LP [19]. They concluded that LP improves the surface roughness of Inconel 718 Selective Laser Melting manufactured parts. On the other hand, Ma et al., also studied the improvement of the surface roughness of additively manufactured Ti alloys [17]. Nevertheless, the reference surface on which authors applied LP was a W-EDM cut surface and not the wavy surface characteristic of AM.

Up to now, the roughness and excess material resulting from the AM process is eliminated mechanically via milling or other abrasive processes, such as grinding. In this direction, the current trend of modern industry is to combine additive and subtractive technologies within the same machine [20]. However, laser-based processes are not always easily combined with other manufacturing techniques. For instance, the combination of LMD with milling or turning may result problematic, especially when cutting fluids are used. The problems arisen can be classified in two groups. On the one hand, the handling and filtering of the moisture generated when the powder particles and the cutting fluid are mixed results problematic. On the other hand, pore phenomena do appear if the surface is not properly cleaned before the LMD process [21].

Consequently, if LMD, LBM and LP processes are combined, the machining operation could be eliminated from the production chain, which leads to a much cleaner and environmentally friendlier manufacture. Moreover, the use of coolants, tooling, etc. is eliminated, which simplifies the management of the generated residues during the manufacturing process.

To demonstrate the validity of this statement, a novel manufacturing procedure, fully based on laser, which combines LMD, LBM and LP technologies is developed, where Laser Beam Machining is employed for removing the overstock and waviness generated by Laser Material Deposition. Finally, LP is used for reducing the roughness resulting from the LBM process. Topographies of the attained surfaces are obtained for each operation and roughness values as well as the microstructure are analyzed to evaluate the surface quality.

\section{Materials and Methods}

The proposed process involves very different laser operations. On the one hand, LMD is usually carried out with Continuous Wave lasers, while LBM and LP are usually performed with pulsed 
lasers. On the other hand, laser beam diameters for LMD are usually between $100 \mu \mathrm{m}$ and $1 \mathrm{~mm}$, while LBM and LP processes used to be carried out with much smaller laser beams (usually below $75 \mu \mathrm{m})$. Therefore, two different machines have been used to perform the proposed procedure. Firstly, the Kondia Aktinos 500 laser center (Kondia, Elgoibar, Spain) coupled with a $1 \mathrm{~kW}$ Rofin FL010 fiber laser (ROFIN-SINAR Laser GmbH, Bergkirchen, Germany) has been employed for the LMD tests. The LMD head includes a $200 \mathrm{~mm}$ focal length lens that concentrates the laser beam in a $0.75 \mathrm{~mm}$ diameter spot, values provided by the laser supplier. Powder material is supplied using a Sulzer Metco Twin $10 \mathrm{C}$ powder feeder (Oerlikon Metco, Pfäffikon, Switzerland) and focused by an in house designed coaxial nozzle, denominated as EHUCoax-2015 (UPV/EHU, Bilbao, Spain) [22]. Argon has been used as protective and carrier gas. Then, a Trumpf TruMark Station 5000 (Trumpf, Ditzingen, Germany) is used for the LBM and LP operations [23]. This marking station has a fiber laser with a Q-switch pulse technology that concentrates a $50 \mathrm{~W}$ laser power in 7-500 ns duration pulses. A 2D galvanometric scanner (Trumpf, Ditzingen, Germany) controls the laser beam position and focuses it at a $212 \mathrm{~mm}$ focal distance and a $45 \mu \mathrm{m}$ diameter; these values are supplied by Trumpf (Ditzingen, Germany).

The material used for the tests is Inconel 718 superalloy, which is supplied by Oerlikon Metco (Pfäffikon, Switzerland) under the name MetcoClad 718. The chemical composition of the powder material is shown in Table 1 and, as it can be observed, it is similar to that of Inconel 718. Powder is supplied with a particle size between 44 and 90 microns in diameter and the spherical shape of the particles is ensured as they are manufactured via Argon-gas atomization.

Table 1. Chemical composition (wt. \%) of the MetcoClad 718 [24].

\begin{tabular}{cccccccccc}
\hline $\mathbf{C r}$ & $\mathbf{M o}$ & $\mathbf{N b}$ & $\mathbf{F e}$ & $\mathrm{Ti}$ & $\mathrm{Si}$ & $\mathbf{M n}$ & $\mathbf{C}$ & $\mathbf{B}$ & $\mathbf{N i}$ \\
\hline 19 & 3 & 5 & 18 & 1 & 0.2 & 0.08 & 0.05 & 0.005 & Bal. \\
\hline
\end{tabular}

Before manufacturing a final test part, three types of tests are performed:

(1) First, a preliminary test (Test Part 1) for evaluating the capability of LBM for machining LMD manufactured Inconel 718 parts is performed. For this purpose, a $3 \mathrm{~mm}$ thickness layer is deposited by means of LMD. Afterwards, the surface of the deposited material is grinded to ensure a flat reference surface. On this surface, different LBM parameters are tested, and, in each case, the reached depth and the resulting surface quality are evaluated. Based on the obtained results, the maximum effective depth at which the laser could remove material is defined.

(2) Secondly, following the same procedure and based on the results obtained in Test 1, the capability of LP for improving the roughness resulting from LBM is evaluated. Based on these results, the optimum LP parameters are defined. Besides, the recast layer generated by LP is measured.

(3) Finally, the capability of LBM for eliminating the surface waviness resulting from LMD is evaluated. In this case, no intermediate grinding operation is performed.

Process parameters for LMD of MetcoClad 718 were obtained in a previous work [21] and they are detailed in Table 2. In Figure 1 a cross section of a single clad is shown, where the dimensions and dilution can be observed. The sample is etched using Kalling's 2 reagent to reveal the microstructure originated during the cooling stage. Generated clads have $2 \mathrm{~mm}$ width and a constant $0.8 \mathrm{~mm}$ height is obtained with each layer. 
Table 2. LMD process parameters for the MetcoClad 718 [21].

\begin{tabular}{cc}
\hline Process Parameter & Value \\
\hline Continuous wave laser power $(\mathrm{W})$ & 570 \\
Scan velocity $\left(\mathrm{mm} \cdot \mathrm{min}^{-1}\right)$ & 525 \\
Track offset $(\mathrm{mm})$ & 1.036 \\
Overlap between tracks $(\%)$ & 26 \\
Powder mass flow $\left(\mathrm{g} \cdot \mathrm{min}^{-1}\right)$ & 8.78 \\
Powder preheating temperature $\left({ }^{\circ} \mathrm{C}\right)$ & 60 \\
Protective gas flow rate $\left(\mathrm{L} \cdot \mathrm{min}^{-1}\right)$ & 14 \\
\hline
\end{tabular}

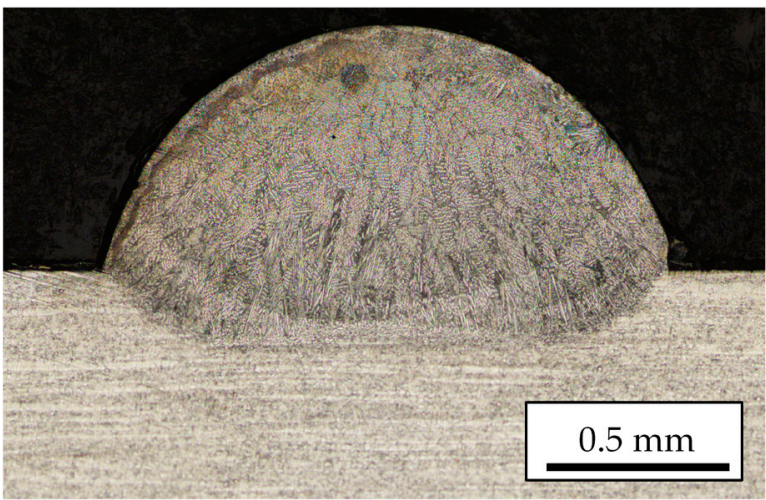

(a)

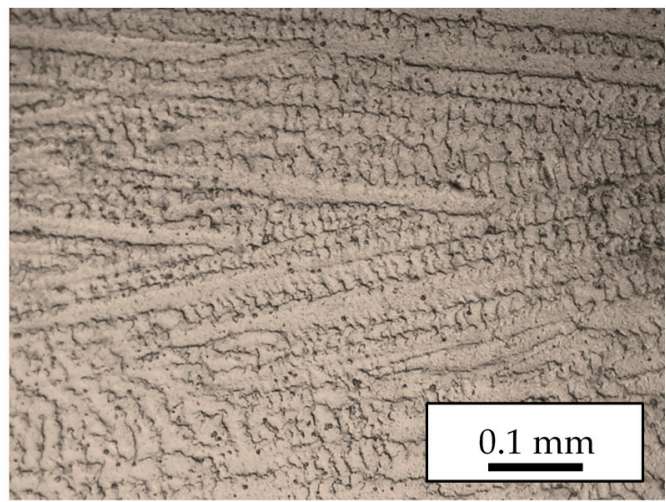

(b)

Figure 1. (a) Cross section of a single clad; (b) Detail of the microstructure.

For the first test, material is deposited over an AISI 1045 substrate. This substrate has no influence on the subsequent LBM operations since they are performed only in the LMD zone. Nevertheless, for the final tests, Inconel 718 substrate is used. Figure 2 shows the substrate with the deposited area after the grinding operation.

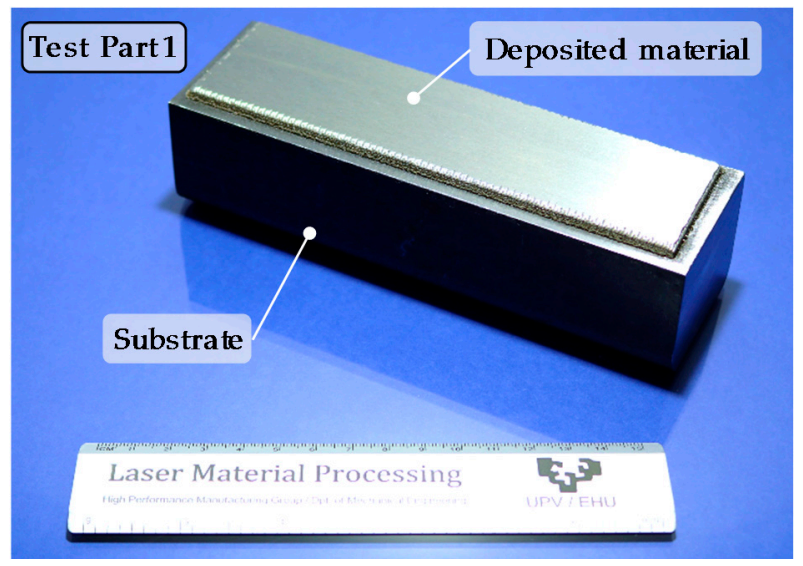

Figure 2. Test part 1 after the LMD and grinding processes.

To determine the best conditions for LBM, a parameter scanning is performed over the grinded flat surface in Test Part 1. Obtained results are shown in Figure 3, whereas the employed parameters in these tests are shown in Table A1 (see Appendix A). 


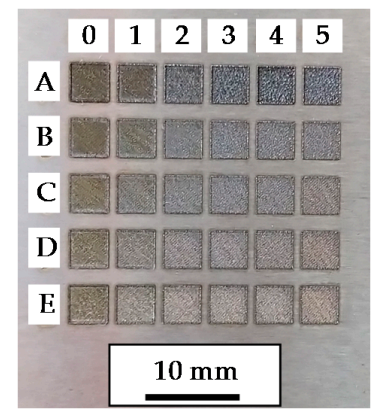

Figure 3. Parameter tests for obtaining the best LBM conditions (Test Part 1).

Likewise, with a view to determining the best LP conditions, a parameter scanning has been performed over the LBM surface resulted from applying the optimum process conditions determined previously, see Figure 4. Test codes for the LP tests are named with lower case letters to avoid misunderstandings with the LBM test naming. The parameters of these tests are showed in Table A2 (see Appendix B).

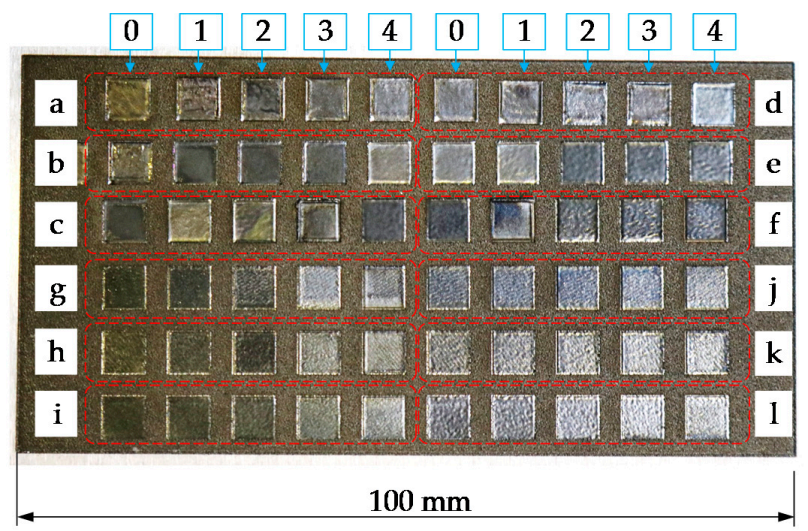

Figure 4. Parameter tests for obtaining the best LP conditions (Test Part 2).

Once Tests 1 and 2 are carried out and the optimum parameters for LBM and LP are defined for an LMD manufactured Inconel 718 part, Test 3 is performed. Test Part 3, which is also used for the manufacture of the Final Test Part, is manufactured layer-by-layer via LMD and the result is a $50 \mathrm{~mm}$ high wall with a $4 \mathrm{~mm}$ thickness and $60^{\circ}$ inclination, see Figure 5. Please note that in this test, no grinding operation is executed and surface waviness resulting from the LMD process is eliminated exclusively via LBM.

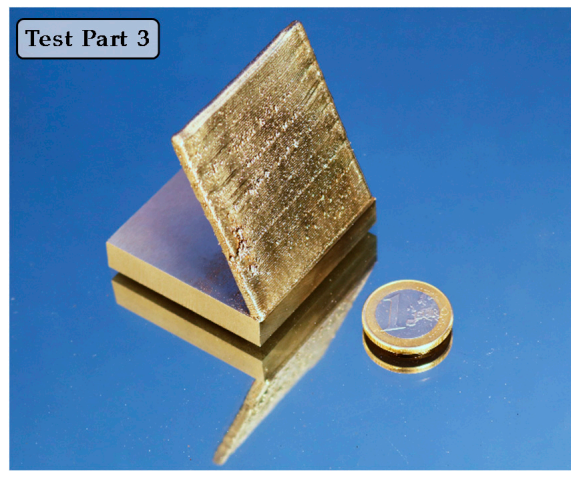

Figure 5. Part manufactured via LMD for Test Part 3. 


\section{Results and Discussion}

\subsection{Material Removal via LBM}

The aim of the LBM operation is to remove as much material as possible from the substrate. Therefore, to determine the optimum parameters for the LBM operation, the depth reached in each case is measured based on the average surface profiles obtained by means of a Leica DCM 3D confocal microscope. The depth reached in each case after a single repetition is detailed in Table 3 , whereas the process conditions employed in each test are detailed in Table A1 (see Appendix A).

Table 3. Depth reached, in microns, after a single repetition for the different LBM process parameters.

\begin{tabular}{cccccc}
\hline Test Code & A & B & C & D & E \\
\hline $\mathbf{0}$ & 52.1 & 10.6 & 4.0 & 5.5 & 6.6 \\
$\mathbf{1}$ & 57.4 & 24.9 & 8.2 & 7.2 & 7.9 \\
$\mathbf{2}$ & 53.5 & 16.9 & 8.3 & 6.5 & 10.9 \\
$\mathbf{3}$ & 54.2 & 27.1 & 7.5 & 7.4 & 9.2 \\
$\mathbf{4}$ & 59.3 & 31.7 & 8.8 & 8.1 & 8.7 \\
$\mathbf{5}$ & 57.3 & 24.5 & 8.2 & 10.5 & 12.5 \\
\hline
\end{tabular}

Process parameters corresponding to the test A4 are considered the best in terms of penetration and low recast layer; therefore, these parameters are employed for the following LBM operations, see Tables 4 and 5 .

Table 4. LBM parameters for the MetcoClad 718.

\begin{tabular}{cc}
\hline Process Parameter & LBM \\
\hline Mean pulse power $(\mathrm{W})$ & 6720 \\
Velocity $\left(\mathrm{mm} \cdot \mathrm{s}^{-1}\right)$ & 800 \\
Pulse frequency $(\mathrm{Hz})$ & 372,000 \\
Pulse duration $(\mathrm{ns})$ & 20 \\
Defocusing $(\mathrm{mm})$ & 0 \\
\hline
\end{tabular}

Table 5. Hatching parameter values for LBM.

\begin{tabular}{cc}
\hline Process Parameter & LBM \\
\hline Line spacing $(\mathrm{mm})$ & 0.05 \\
Number of hatchings $(-)$ & 20 \\
Angle increment $\left(^{\circ}\right)$ & 17 \\
\hline
\end{tabular}

Once the process parameters are determined, LBM is performed on the surface of the Test Part 1, with the laser beam focused on its surface and without changing the focal position between the consecutive repetitions. After every 10 repetitions, the mark generated on the surface of the substrate is analyzed by means of a Leica DCM 3D confocal microscope. In Figure 6, the topographies of two different marks are shown.

As the number of repetitions is increased, the depth increment is lower, and after 100 repetitions, it is noticed that the laser is not capable of removing material anymore. Therefore, the LBM process is concluded to be capable of removing material until a $1.6 \mathrm{~mm}$ maximum distance from the focal plane position (fpp), see Figure 7. It must be highlighted that the laser beam is focused on the original grinded surface of the substrate and its position remains unchanged as the number of repetitions is increased. 


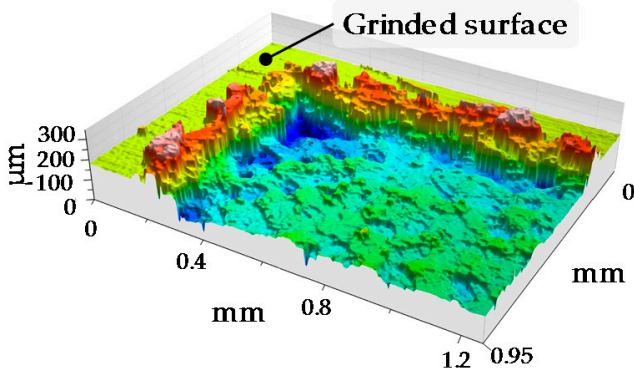

(a)

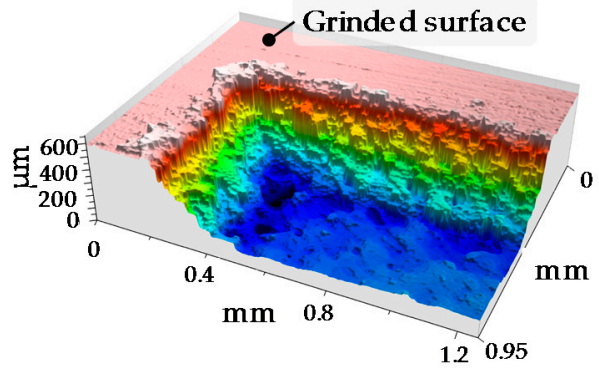

(b)

Figure 6. Topographies of the mark after (a) One repetition; (b) 10 repetitions.

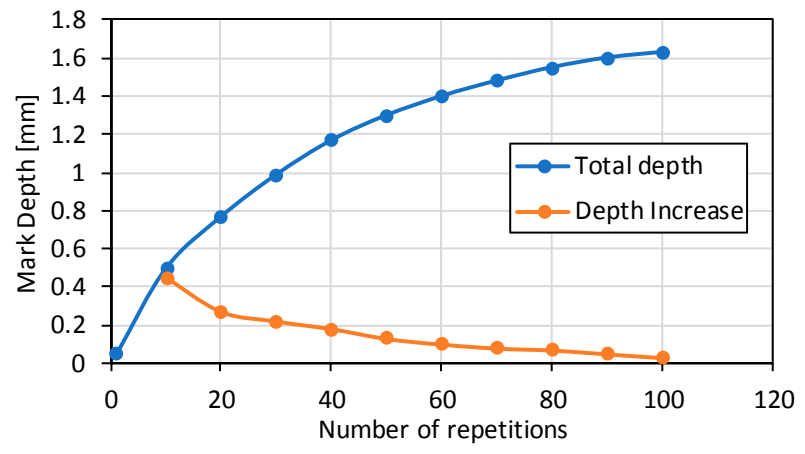

Figure 7. Depth increase as the number of repetitions is increased.

Besides, the time required for processing a $1 \mathrm{~cm}^{2}$ area until a $0.08 \mathrm{~mm}$ depth is of $507.31 \mathrm{~s}$, which results in a $8.3 \times 10^{-3} \mathrm{~g} \cdot \mathrm{min}^{-1}$ material removal rate in the LBM process.

\subsection{Roughness Reduction via LP}

In Test 2, the roughness resulting from Test 1 is reduced via LP. With the aim of determining the optimum LP parameters, the resulting Ra roughness is measured in every polished square shown in Figure 4. Roughness measurements are performed according to the standard ISO 4287 and using a Leica DCM 3D confocal microscope. The resulting Ra values in microns are detailed in Table 6, whereas the process conditions employed in each test are shown in Table A2 (see Appendix B).

Table 6. Ra value, in microns, after the different LP tests.

\begin{tabular}{cccccc}
\hline Test Code & $\mathbf{0}$ & $\mathbf{1}$ & $\mathbf{2}$ & $\mathbf{3}$ & $\mathbf{4}$ \\
\hline $\mathbf{a}$ & 1.12 & 0.98 & 0.79 & 0.87 & 1.54 \\
$\mathbf{b}$ & 0.95 & 0.90 & 0.67 & 0.77 & 1.42 \\
$\mathbf{c}$ & 0.91 & 0.89 & 0.68 & 0.75 & 1.38 \\
$\mathbf{d}$ & 1.15 & 1.03 & 0.83 & 0.72 & 1.61 \\
$\mathbf{e}$ & 0.98 & 0.93 & 0.72 & 0.72 & 1.45 \\
$\mathbf{f}$ & 0.93 & 0.92 & 0.75 & 0.62 & 1.41 \\
$\mathbf{g}$ & 1.34 & 1.18 & 0.95 & 1.04 & 1.89 \\
$\mathbf{h}$ & 1.14 & 1.04 & 0.80 & 0.89 & 1.70 \\
$\mathbf{i}$ & 1.09 & 1.05 & 0.82 & 0.90 & 1.74 \\
$\mathbf{j}$ & 1.36 & 1.24 & 0.95 & 0.86 & 2.03 \\
$\mathbf{k}$ & 1.18 & 1.10 & 0.86 & 0.85 & 1.74 \\
$\mathbf{1}$ & 1.10 & 1.10 & 0.90 & 0.74 & 1.78 \\
\hline
\end{tabular}

After the results analysis, it is concluded that for the same process parameters (laser power, frequency, hatching, defocus, etc.) an increase of the laser scan velocity results directly in higher 
surface roughness. Besides, it is also noticed that the surface roughness improves as the laser frequency is increased, but $200 \mathrm{kHz}$ becomes a limit value, after which Ra value increases.

Regarding the number of hatches used for polishing, the resulting roughness value is improved as the number of repetitions is increased and a lower Ra value is obtained in all cases with 10 repetitions rather than with 5. However, when the number of repetitions is further increased, until 20, there is no considerable roughness reduction, whereas the required time for the process is doubled. Hence, it is decided that 10 repetitions is the optimum parameter tested.

Process parameters corresponding to the test $\mathrm{b} 2$ provided the lowest roughness value, and therefore, these parameters are employed for the following LP operations, see Tables 7 and 8 . Notice that due to the $4 \mathrm{~mm}$ defocusing, the laser spot becomes approximately 120 microns in diameter at the working plane.

Table 7. LP parameters for the MetcoClad 718.

\begin{tabular}{cc}
\hline Process Parameter & LP \\
\hline Mean pulse power $(\mathrm{W})$ & 621 \\
Velocity $\left(\mathrm{mm} \cdot \mathrm{s}^{-1}\right)$ & 100 \\
Pulse frequency $(\mathrm{Hz})$ & 175,000 \\
Pulse duration $(\mathrm{ns})$ & 460 \\
Defocusing $(\mathrm{mm})$ & 4 \\
\hline
\end{tabular}

Table 8. Hatching parameter values for LP.

\begin{tabular}{cc}
\hline Process Parameter & LP \\
\hline Line spacing $(\mathrm{mm})$ & 0.02 \\
Number of hatchings $(-)$ & 10 \\
Angle increment $\left(^{\circ}\right)$ & 36 \\
\hline
\end{tabular}

The idea of combining LMD and LBM processes arises as a methodology aiming to remove the surface waviness that LMD generates, and thus, obtain a flat surface. To that end, the laser is defocused $1 \mathrm{~mm}$ above the desired final surface. Therefore, the laser eliminates all material until a distance of $1.6 \mathrm{~mm}$ from the focal plane position, see Figure 8 , and the process does only affect material located in this concrete region. However, as the resulting surface quality from the LBM process has a high roughness value, a polishing stage is afterwards performed.

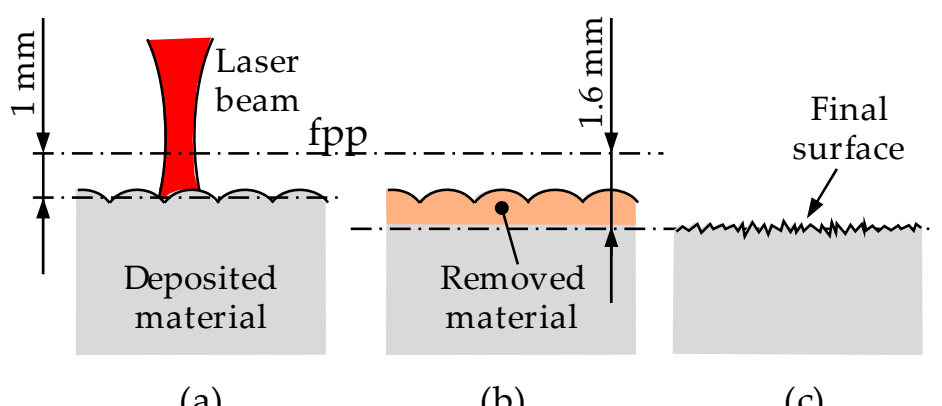

(a)

(b)

(c)

Figure 8. Followed strategy in LBM for obtaining a flat surface from the waved LMD surface. (a) LMD manufactured part; (b) Material removal via LBM; (c) Resulting flat surface after LBM.

A 3D view of the surfaces attained after the different laser-based processes are shown in Figures 9-11. In the three figures, the same height axis scale is used to make results visually comparable. In the case of the LMD surface, roughness is measured perpendicularly to the LMD direction, because LMD is a directional process and so is the resulting surface pattern. On the contrary, 
in LBM and LP the hatching direction is changed in every repetition to avoid any directional pattern on the surface, and therefore, roughness is independent from the measured direction.

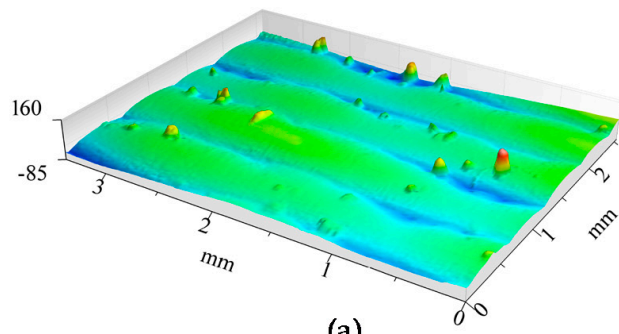

(a)

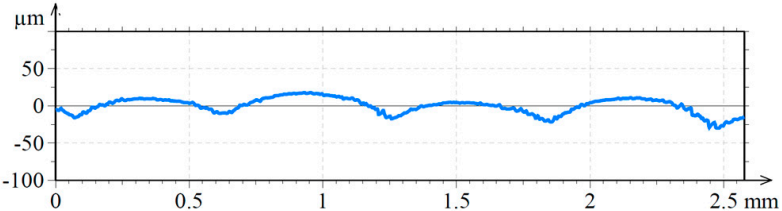

(b)

Figure 9. (a) Topography and (b) surface profile LMD.

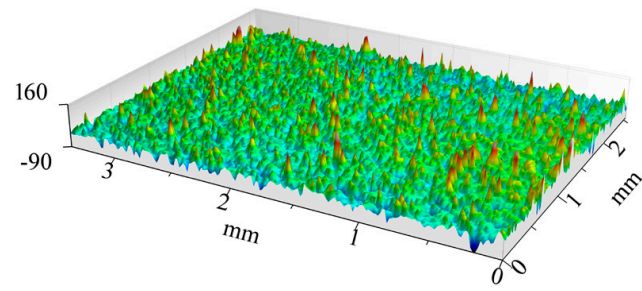

(a)

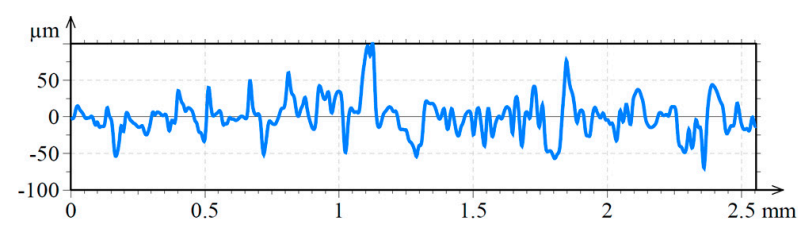

(b)

Figure 10. (a) Topography and (b) surface profile LMD + LBM.

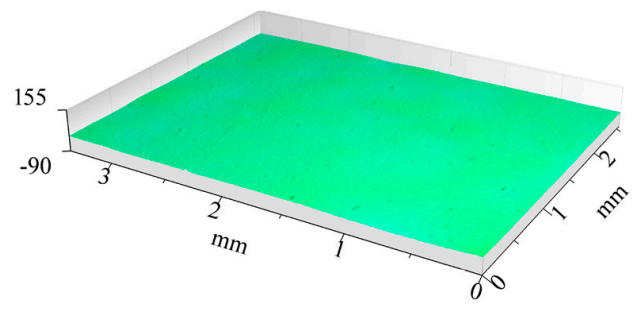

(a)

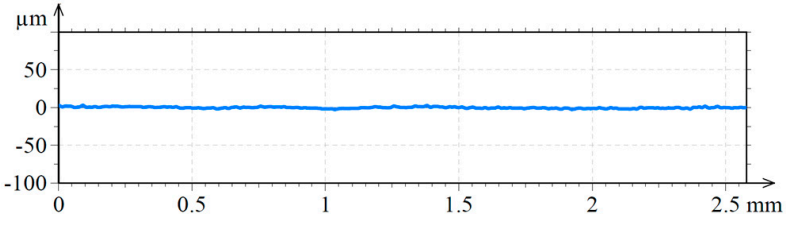

(b)

Figure 11. (a) Topography and (b) surface profile LMD + LBM + LP.

In a second step, to compare numeric roughness values, the roughness of each surface is obtained. For this purpose, the arithmetic mean deviation of the surface roughness (Ra) of five different profiles is measured in each surface and the average value is calculated. Measurements are performed according to the standard ISO 4287. As it is shown in Table 9, the Ra value is higher after the LBM process, than that after LMD. However, LBM provides a waviness-free surface, but the roughness needs to be reduced with the subsequent polishing stage.

Table 9. Arithmetic Mean Deviation of the Roughness Profile (Ra) in microns, according to ISO 4287. $0.25 \mathrm{~mm}$ Gaussian filter applied.

\begin{tabular}{cccc}
\hline Measurement & LMD & LBM & LM \\
\hline 1 & 1.56 & 20.45 & 0.53 \\
2 & 2.38 & 20.24 & 0.66 \\
3 & 1.32 & 20.21 & 0.57 \\
4 & 1.85 & 24.80 & 0.71 \\
5 & 2.01 & 16.17 & 0.56 \\
Average Ra & 1.82 & 20.37 & 0.61 \\
\hline
\end{tabular}




\subsection{Influence of the LP on Material Microstructure}

LP is proved to be capable of modifying the surface roughness. However, it also affects the microstructure of the material and generates a recast layer that may modify the mechanical properties of the final part. To evaluate the influence of the LP on the microstructure, both LBM and LBM + LP surfaces have been cross-sectioned, polished, and etched using Kalling's 2 reagent. Notice that the polished surface shown in Figure 12b is the same LBM surface shown in Figure 12a that has been later subjected to LP. The thickness of the recast layer due to the polishing is of $22 \mu \mathrm{m}$, which is a circumstance to be considered depending on the final application of the part.

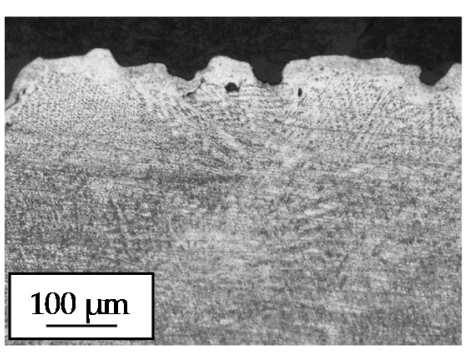

(a)

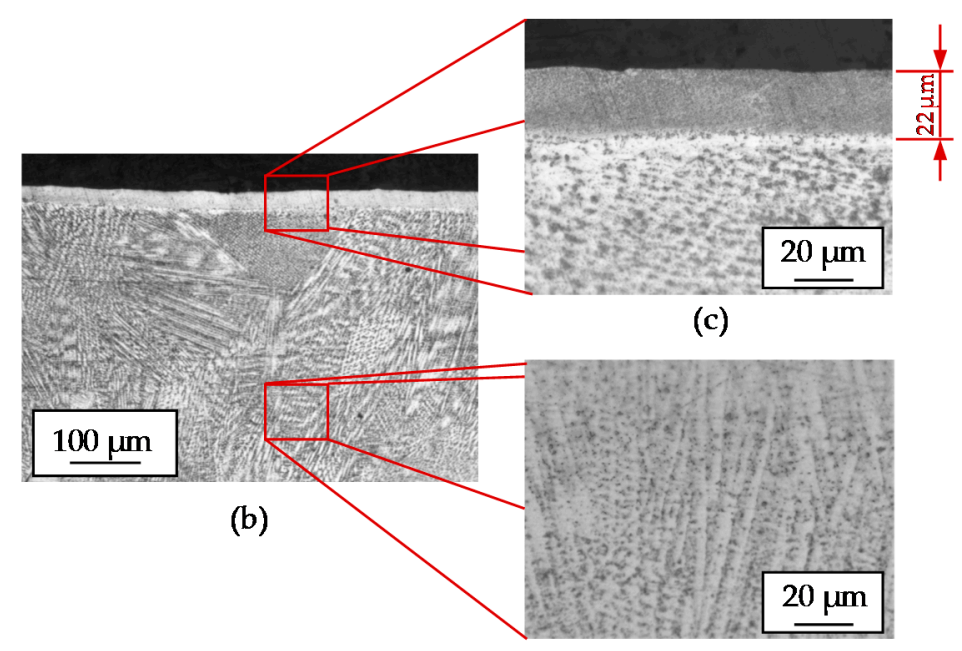

(d)

Figure 12. (a) Cross section of the LBM manufactured surface; (b) Cross section of the LBM + LP manufactured surface; (c) Detail of the recast layer generated on the surface due to polishing; (d) Internal microstructure developed as a result of the LMD process.

\subsection{Final Test Part}

To demonstrate the potential of combining LMD, LBM and LP processes, a final test part is manufactured, Figure 13. First, starting from an Inconel 718 substrate, an oblique wall is built using MetcoClad 718 filler material with the same strategy and conditions used in the previous tests. Afterwards, the wavy surface resulting from the LMD is processed via LBM up to a $0.5 \mathrm{~mm}$ depth. Finally, the desired regions are laser polished.

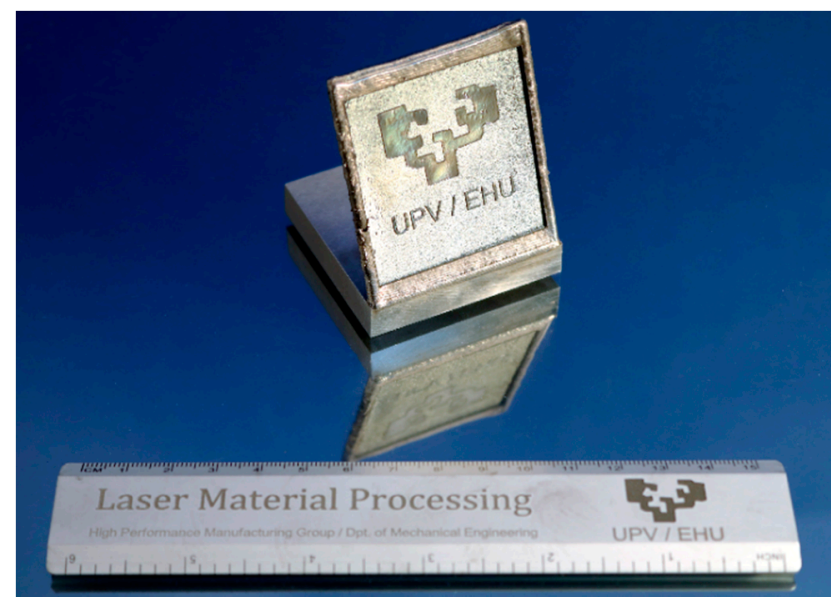

Figure 13. Final shape of the manufactured final test part. 


\section{Conclusions}

In the present work, a full laser-based manufacturing technique is proposed. According to the attained results, the following conclusions are drawn:

(1) The LBM process is proved capable of eliminating the waviness generated in the LMD process and enables to obtain a flat surface.

(2) Surface quality resulting from LBM may not comply with the desired requirements. However, high surface quality (N5-N6 roughness grade) is obtained after the LP stage.

(3) LP generates a recast layer with a thickness of $22 \mu \mathrm{m}$. Depending on the final application of the part, this circumstance must be considered, because it might be detrimental to the mechanical properties. Further investigations must be performed to determine the influence of this recast layer.

(4) In LBM a maximum material removal rate of $8.3 \times 10^{-3} \mathrm{~g} \cdot \mathrm{min}^{-1}$ is obtained. Therefore, LBM is proved to be slow when compared with the machining processes. Consequently, the combination of LMD + LBM is only advantageous when difficult-to-cut materials are processed, or high-resolution detail operations are required.

(5) The LBM process is capable of manufacturing small details that may not be possible to attain with other traditional machining processes, such as milling.

Author Contributions: Conceptualization and methodology, J.I.A.; LMD experiments, M.C.; engraving experiments, J.I.A.; polishing experiments, J.E.R.; Analysis of the obtained data, J.I.A., M.C. and J.E.R.; Writing-Original Draft Preparation, J.I.A.; Supervision, A.L.

Acknowledgments: Special thanks are addressed to the Industry and Competitiveness Spanish Ministry for the support on the DPI2016-79889-R INTEGRADDI project and PARADDISE project H2020-IND-CE-2016-17/H2020-FOF-2016 of the European Union's Horizon 2020 research and innovation program.

Conflicts of Interest: The authors declare no conflict of interest.

\section{Appendix A}

Process parameters for LBM tests carried out to determine the optimal parameters are detailed in Table A1. In all tests, the hatching parameters are kept constant according to the values detailed in Table 4 (line spacing of $0.05 \mathrm{~mm}$ and 20 hatching with an angle increment of $17^{\circ}$ ). Test codes for the LBM tests are named with upper case letters.

Table A1. LBM process parameters.

\begin{tabular}{ccccc}
\hline Test & Velocity $\left[\mathbf{m m} \cdot \mathbf{s}^{-\mathbf{1}}\right]$ & Defocusing $\mathbf{( m m )}$ & Pulse Frequency [Hz] & Pulse Duration [ns] \\
\hline A0 & 800 & 0 & 144,000 & 55 \\
A1 & 800 & 0 & 201,000 & 37 \\
A2 & 800 & 0 & 258,000 & 27 \\
A3 & 800 & 0 & 315,000 & 23 \\
A4 & 800 & 0 & 372,000 & 17 \\
A5 & 800 & 0 & 429,000 & 55 \\
B0 & 1100 & 0 & 144,000 & 37 \\
B1 & 1100 & 0 & 201,000 & 27 \\
B2 & 1100 & 0 & 258,000 & 23 \\
B3 & 1100 & 0 & 315,000 & 20 \\
B4 & 1100 & 0 & 372,000 & 17 \\
B5 & 1100 & 0 & 429,000 & 55 \\
C0 & 1400 & 0 & 144,000 & 37 \\
C1 & 1400 & 0 & 201,000 & \\
\hline
\end{tabular}


Table A1. Cont.

\begin{tabular}{ccccc}
\hline Test & Velocity $\left[\mathbf{m m} \cdot \mathbf{s}^{-\mathbf{1}}\right.$ ] & Defocusing $(\mathbf{m m})$ & Pulse Frequency [Hz] & Pulse Duration [ns] \\
\hline C2 & 1400 & 0 & 258,000 & 27 \\
C3 & 1400 & 0 & 315,000 & 23 \\
C4 & 1400 & 0 & 372,000 & 20 \\
C5 & 1400 & 0 & 429,000 & 17 \\
D0 & 1700 & 0 & 144,000 & 55 \\
D1 & 1700 & 0 & 201,000 & 37 \\
D2 & 1700 & 0 & 258,000 & 27 \\
D3 & 1700 & 0 & 315,000 & 23 \\
D4 & 1700 & 0 & 372,000 & 20 \\
D5 & 1700 & 0 & 429,000 & 17 \\
E0 & 2000 & 0 & 144,000 & 55 \\
E1 & 2000 & 0 & 201,000 & 37 \\
E2 & 2000 & 0 & 258,000 & 27 \\
E3 & 2000 & 0 & 315,000 & 23 \\
E4 & 2000 & 0 & 372,000 & 20 \\
E5 & 2000 & 0 & 429,000 & 17 \\
\hline
\end{tabular}

\section{Appendix B}

Process parameters for LP are shown in the following Table A2. In all tests, the line spacing is kept constant with a value of $0.02 \mathrm{~mm}$. The angle increment between the hatchings is defined to sweep a total angle of $360^{\circ}$ with the defined number of hatches. Test codes for the LP tests are named with lower case letters.

Table A2. LP process parameters.

\begin{tabular}{cccccc}
\hline Test & $\begin{array}{c}\text { Velocity } \\
{\left[\mathbf{m m} \cdot \mathbf{s}^{-\mathbf{1}}\right]}\end{array}$ & $\begin{array}{c}\text { Defocusing } \\
{[\mathbf{m m}]}\end{array}$ & $\begin{array}{c}\text { Number of } \\
\text { Hatches }\end{array}$ & $\begin{array}{c}\text { Angle Increment } \\
\left.\text { between Hatchings [ }{ }^{\circ}\right]\end{array}$ & $\begin{array}{c}\text { Pulse Frequency } \\
{[\text { Hz] }}\end{array}$ \\
\hline a0 & 100 & 4 & 5 & 72 & 125,000 \\
a1 & 100 & 4 & 5 & 72 & 150,000 \\
a2 & 100 & 4 & 5 & 72 & 175,000 \\
a3 & 100 & 4 & 5 & 72 & 200,000 \\
a4 & 100 & 4 & 5 & 36 & 225,000 \\
b0 & 100 & 4 & 10 & 36 & 125,000 \\
b1 & 100 & 4 & 10 & 36 & 150,000 \\
b2 & 100 & 4 & 10 & 36 & 175,000 \\
b3 & 100 & 4 & 10 & 36 & 200,000 \\
b4 & 100 & 4 & 10 & 18 & 125,0000 \\
c0 & 100 & 4 & 20 & 18 & 150,000 \\
c1 & 100 & 4 & 20 & 18 & 175,000 \\
c2 & 100 & 4 & 20 & 18 & 200,000 \\
c3 & 100 & 4 & 20 & 18 & 225,000 \\
c4 & 100 & 4 & 20 & 72 & 125,000 \\
d0 & 100 & 5 & 5 & 72 & 150,000 \\
d1 & 100 & 5 & 5 & 72 & 175,000 \\
d2 & 100 & 5 & 5 & 72 & 200,000 \\
d3 & 100 & 5 & 5 & 72 & 225,000 \\
d4 & 100 & 5 & 5 & 36 & 125,000 \\
e0 & 100 & 5 & 10 & 36 & 150,000 \\
e1 & 100 & 5 & 10 & 36 & 175,000 \\
e2 & 100 & 5 & 10 & 36 & 200,000 \\
e3 & 100 & 5 & 10 & 36 & 225,000 \\
e4 & 100 & 5 & 10 & 18 & 125,000 \\
f0 & 100 & 5 & 20 & & \\
\hline
\end{tabular}


Table A2. Cont.

\begin{tabular}{|c|c|c|c|c|c|}
\hline Test & $\begin{array}{l}\text { Velocity } \\
{\left[\mathrm{mm} \cdot \mathrm{s}^{-1}\right]}\end{array}$ & $\begin{array}{l}\text { Defocusing } \\
\text { [mm] }\end{array}$ & $\begin{array}{c}\text { Number of } \\
\text { Hatches }\end{array}$ & $\begin{array}{c}\text { Angle Increment } \\
\text { between Hatchings }\left[{ }^{\circ}\right]\end{array}$ & $\begin{array}{c}\text { Pulse Frequency } \\
{[\mathrm{Hz}]}\end{array}$ \\
\hline $\mathrm{f} 1$ & 100 & 5 & 20 & 18 & 150,000 \\
\hline $\mathrm{f} 2$ & 100 & 5 & 20 & 18 & 175,000 \\
\hline $\mathrm{f} 3$ & 100 & 5 & 20 & 18 & 200,000 \\
\hline $\mathrm{f} 4$ & 100 & 5 & 20 & 18 & 225,000 \\
\hline g0 & 200 & 4 & 5 & 72 & 125,000 \\
\hline g1 & 200 & 4 & 5 & 72 & 150,000 \\
\hline g2 & 200 & 4 & 5 & 72 & 175,000 \\
\hline g3 & 200 & 4 & 5 & 72 & 200,000 \\
\hline g4 & 200 & 4 & 5 & 72 & 225,000 \\
\hline h0 & 200 & 4 & 10 & 36 & 125,000 \\
\hline h1 & 200 & 4 & 10 & 36 & 150,000 \\
\hline h2 & 200 & 4 & 10 & 36 & 175,000 \\
\hline h3 & 200 & 4 & 10 & 36 & 200,000 \\
\hline h4 & 200 & 4 & 10 & 36 & 225,000 \\
\hline i0 & 200 & 4 & 20 & 18 & 125,000 \\
\hline i1 & 200 & 4 & 20 & 18 & 150,000 \\
\hline i2 & 200 & 4 & 20 & 18 & 175,000 \\
\hline i3 & 200 & 4 & 20 & 18 & 200,000 \\
\hline i4 & 200 & 4 & 20 & 18 & 225,000 \\
\hline j0 & 200 & 5 & 5 & 72 & 125,000 \\
\hline j1 & 200 & 5 & 5 & 72 & 150,000 \\
\hline j2 & 200 & 5 & 5 & 72 & 175,000 \\
\hline j3 & 200 & 5 & 5 & 72 & 200,000 \\
\hline $\mathrm{j} 4$ & 200 & 5 & 5 & 72 & 225,000 \\
\hline $\mathrm{k} 0$ & 200 & 5 & 10 & 36 & 125,000 \\
\hline k1 & 200 & 5 & 10 & 36 & 150,000 \\
\hline k2 & 200 & 5 & 10 & 36 & 175,000 \\
\hline 13 & 200 & 5 & 10 & 36 & 200,000 \\
\hline 14 & 200 & 5 & 10 & 36 & 225,000 \\
\hline 10 & 200 & 5 & 20 & 18 & 125,000 \\
\hline 11 & 200 & 5 & 20 & 18 & 150,000 \\
\hline 12 & 200 & 5 & 20 & 18 & 175,000 \\
\hline 13 & 200 & 5 & 20 & 18 & 200,000 \\
\hline 14 & 200 & 5 & 20 & 18 & 225,000 \\
\hline
\end{tabular}

\section{References}

1. Steen, W.M.; Mazumder, J. Laser Material Processing, 4th ed.; Springer: London, UK, 2010; ISBN 978-1-84996-062-5.

2. Cortina, M.; Arrizubieta, J.I.; Calleja, A.; Ukar, E.; Alberdi, A. Case study to illustrate the potential of conformal cooling channels for hot stamping dies manufactured using hybrid process of Laser Metal Deposition (LMD) and milling. Metals 2018, 8, 102. [CrossRef]

3. Klocke, F.; Klink, A.; Veselovac, D.; Aspinwall, D.K.; Soo, S.L.; Schmidt, M.; Schilp, J.; Levy, G.; Kruth, J.P. Turbomachinery component manufacture by application of electrochemical, electro-physical and photonic processes. CIRP Ann.-Manuf. Technol. 2014, 63, 703-726. [CrossRef]

4. Ashby, M.F. Materials and the Environment: Eco-Informed Material Choice; Butterworth-Heinemann: Oxford, UK, 2012; ISBN 9780123859716.

5. Ingarao, G.; Priarone, P.C.; Deng, Y.; Paraskevas, D. Environmental modelling of aluminium based components manufacturing routes: Additive manufacturing versus machining versus forming. J. Clean. Prod. 2018, 176, 261-275. [CrossRef]

6. Caiazzo, F.; Alfieri, V.; Corrado, G.; Argenio, P.; Barbieri, G.; Acerra, F.; Innaro, V. Laser Beam Welding of a Ti-6Al-4V Support Flange for Buy-to-Fly Reduction. Metals 2017, 7, 183. [CrossRef]

7. Gasser, A. Chapter 11.6: Laser Metal Deposition. In Tailored Light 2, Laser Application Technology; Poprawe, R., Ed.; Springer: Berlin/Heidelberg, Germany, 2011; pp. 216-224, ISBN 978-3-642-01236-5. 
8. Dubey, A.K.; Yadava, V. Laser beam machining-A review. Int. J. Mach. Tools Manuf. 2018, 48, 609-628. [CrossRef]

9. Borse, S.C.; Kadam, M.S. Experimental Study in Micromilling of Inconel 718 by Fiber Laser Machining. Procedia Manuf. 2018, 20, 213-218. [CrossRef]

10. Yilbas, B.S. Laser Machining Processes. In Reference Module in Materials Science and Materials Engineering, from Comprehensive Materials Finishing; Elsevier: New York, NY, USA, 2017; Volume 1, pp. 344-363.

11. Lee, S.W.; Shin, H.S.; Chu, C.N. Fabrication of micro-pin array with high aspect ratio on stainless steel using nanosecond laser beam machining. Appl. Surf. Sci. 2013, 264, 653-663. [CrossRef]

12. Kononenko, T.V.; Freitag, C.; Sovyk, D.N.; Lukhter, A.B.; Skvortsov, K.V.; Konov, V.I. Influence of pulse repetition rate on percussion drilling of Ti-based alloy by picosecond laser pulses. Opt. Lasers Eng. 2018, 103, 65-70. [CrossRef]

13. Peng, C.; Fu, Y.; Wei, H.; Li, S.; Wang, X.; Gao, H. Study on improvement of surface roughness and induced residual stress for Additively Manufactured metal parts by Abrasive Flow Machining. Procedia CIRP 2018, 71, 386-389. [CrossRef]

14. Willenborg, E. Chapter 11.3: Polishing with Laser Radiation. In Tailored Light 2, Laser Application Technology; Poprawe, R., Ed.; Springer: Berlin/Heidelberg, Germany, 2011; pp. 196-202, ISBN 978-3-642-01236-5.

15. Alfieri, V.; Argenio, P.; Caiazzo, F.; Sergi, V. Reduction of Surface Roughness by Means of Laser Processing over Additive Manufacturing Metal Parts. Materials 2017, 10, 30. [CrossRef] [PubMed]

16. Dewey, M.P.; Ulutan, D. Development of Laser Polishing as an Auxiliary Post-Process to Improve Surface Quality in Fused Deposition Modeling Parts. In Proceedings of the ASME 12th International Manufacturing Science and Engineering Conference, Los Angeles, CA, USA, 4-8 June 2017; Volume 2. [CrossRef]

17. Ma, C.P.; Guan, Y.C.; Zhou, W. Laser polishing of additive manufactured Ti alloys. Opt. Lasers Eng. 2017, 93, 171-177. [CrossRef]

18. Marimuthu, S.; Triantaphyllou, A.; Antar, M.; Wimpenny, D.; Morton, H.; Beard, M. Laser polishing of selective laser melted components. Int. J. Mach. Tools Manuf. 2015, 95, 97-104. [CrossRef]

19. Zhihao, F.; Libin, L.; Longfei, C.; Yingchun, G. Laser Polishing of additive Manufactured Superalloy. Procedia CIRP 2018, 71, 150-154. [CrossRef]

20. Flynn, J.M.; Shokrani, A.; Newman, S.T.; Dhokia, V. Hybrid additive and subtractive machine tools-Research and industrial developments. Int. J. Mach. Tools Manuf. 2016, 101, 79-101. [CrossRef]

21. Cortina, M.; Arrizubieta, J.I.; Ukar, E.; Lamikiz, A. Analysis of the Influence of the Use of Cutting Fluid in Hybrid Processes of Machining and Laser Metal Deposition (LMD). Coatings 2018, 8, 61. [CrossRef]

22. Arrizubieta, J.I.; Tabernero, I.; Ruiz, J.E.; Lamikiz, A.; Martínez, S.; Ukar, E. Continuous coaxial nozzle design for LMD based on numerical simulation. Phys. Procedia 2014, 56, 429-438. [CrossRef]

23. TruMark Station 5000. Available online: https://www.trumpf.com/en_INT/products/machines-systems / marking-systems / trumark-station-5000/ (accessed on 11 June 2018).

24. Oerlikon Metco. MetcoClad 718 Material Product Data Sheet; Oerlikon Metco: Pfäffikon, Switzerland, 2018. Available online: https://www.oerlikon.com/ecomaXL/files/metco/oerlikon_DSMW-0002.6_ NiSuperalloys_LaserCladding.pdf\&download=1 (accessed on 11 June 2018).

(C) 2018 by the authors. Licensee MDPI, Basel, Switzerland. This article is an open access article distributed under the terms and conditions of the Creative Commons Attribution (CC BY) license (http://creativecommons.org/licenses/by/4.0/). 